\title{
European Science Cut Four Ways
}

A FAR-REACHING reorganization of responsibilities for science and technology within the European Community has followed on the addition of Britain, Denmark and Ireland to the community.

The wide-ranging responsibilities held by $\mathrm{Mr}$ Altiero Spinelli until Sunday's meeting of the new commission have now been parcelled out among four commissioners. Mr Spinelli had been in charge of what were labelled industrial, technological and scientific affairs but also included a small education unit. Now Mr Spinelli is responsible only for industrial and technological affairs, and Dr Ralf Dahrendorf of West Germany, formerly commissioner for external relations and trade, has taken over scientific research matters and education. Energy policy, and those aspects of Euratom's work that affect energy policy, formerly the responsibility of $\mathrm{Mr}$ Wilhelm Haferkamp, now fall under Mr Henri Simonet, the Belgian commissioner, while Mr Carlo Scarascia Mugnozza, the second Italian commissioner, is to have a wide-ranging brief including environmental matters, transport and consumer interests as well as public information.

These are early days, and the full implication of the changes will not become apparent at least until the directors-general and the directors have been appointed, but it is thought that Mr Mugnozza could build for himself a powerful brief in the field loosely termed the "quality of life". But it is into Dr Ralf Dahrendorf's hands that the bulk of scientific matters now falls. $\mathrm{He}$ is to have responsibility for the muchtroubled Joint Research Centre that is the nub of Euratom, and his first problem will come to a head on January 18 , when the commission's plans for reducing Euratom's size come up again for consideration in Brussels.

The commission is acutely aware of Euratom's failings, and there is also a feeling that the JRC is too big for the job that is left for it. Fundamental research on nuclear power has suffered from the way in which national interests have set off independently in producing nuclear power plants, and the JRC, with 2,000 staff and four centres in Italy, the Netherlands, Germany and Belgium, has not enough work to keep itself occupied. Plans to move the JRC into general contract research for industry on the now familiar lines of the UKAEA's Harwell establishment fell down because Euratom's founding treaty permits virtually nothing to be done within Euratom except nuclear research.

The community is unwilling to continue funding such an expensive enterprise ( $\$ 44$ million in 1972), but running it down is difficult as its scientists are European civil servants. Nevertheless the commission has produced plans to close the Dutch centre at Petten which concentrates on materials testing and significantly to reduce the numbers at the Italian centre at Ispra-by far the largest of the four centres, currently employing about 1,200 people. The objective is to reduce the total staff to about 1,600 . This may not be radical enough. At a meeting in December, it became apparent that the French and German governments want the staff at the JRC reduced still further to about 1,200 , and the fear in the commission is that unless a compromise is reached, the JRC could be cut back so heavily that it will be unable to fulfil any useful function. Sorting out this knotty problem, not to mention the complicated financing of the centre, is now on Dr Dahrendorf's plate, although $\mathrm{Mr}$ Spinelli will in fact be batting for what are essentially his proposals at the January meeting.

\section{CRIMOND TERMINAL}

\section{Consultation Begins}

THE Gas Council and Total Oil Marine are to hold talks with the objectors to their scheme to build a gas terminal by a site of scientific importance.

Following a meeting with Aberdeen County Council's countryside committee this week, it was agreed that representatives of the industry will provide answers to specific queries about the application put to it by the committee, and that they will meet representatives of the scheme's opponents including the Environmental Liaison Group that has been set up around the university.

The proposal to build a gas terminal at Crimond airfield above Loch Strathbeg first came to light in December when the Gas Council and Total Oil Marine applied for planning permission. Fourteen days were given for objections to the scheme to reach the planning committee. In that time more than $\mathbf{1 7 0}$ objections, some of them protest petitions, reached the planning committee
Dr Dahrendorf is also to have the task of trying to "harmonize"--a favourite European word-the various qualifications and degrees that are earned around Europe.

The separation of science and research from technology and industry-technology apparently includes research on such matters as aerospace and computers-could improve the chances for the European Science Foundation, and could ensure a commitment to fundamental research stronger than might have been the case within a brief including technology and industry. On the face of things, Dr Dahrendorf's responsibilities for science would appear not dissimilar to the scope of activities of the British Government's Department of Education and Science.

\section{METEOROLOGY}

\section{Cloud Seeding Attacked}

IN a sweeping attack on ill-conceived attempts at weather modification, Dr B. J. Mason, Director-General of the UK Meteorological Office, has warned that the reputation of meteorology could be severely damaged and that the science could become embroiled in inter-

which decided to postpone a decision until more was known of the proposal.

Loch Strathbeg is classified as a site of scientific importance on wildlife, physical and limnological grounds, and the scheme's opponents are eager that the site should be preserved because of its international importance.

The planning committee is due to meet next on January 22 , by which time the Gas Council and Total will have met the objectors to see if "safeguards can be evolved to allow the planning proposal to go ahead", according to $\mathrm{Mr}$ John Russell, Aberdeen's county clerk.

The key to the problem, it appears, is that the submarine relief and the nature of the sediments off the north-east coast of Scotland are among the crucial factors in deciding where the pipeline is to come ashore. One off-shore survey was completed last summer, but other surveys are still in progress and as far as Professor Kenneth Walton, professor of geography at the University of Aberdeen, is concerned "there is still not sufficient information available on which to base a firm conclusion". 